\title{
VIOLÊNCIA URBANA: CRIMINALIZAÇÃO DA POBREZA E A DISPUTA TERRITORIAL DO TRÁFICO DE DROGAS
}

\author{
URBAN VIOLENCE: CRIMINALIZATION OF POVERTY AND \\ TERRITORIAL DISPUTE OF DRUG TRAFFICKING \\ Warllon de Souza Barcellos ${ }^{1}$ \\ Ana Claudia de Jesus Barreto ${ }^{2}$
}

\section{RESUMO}

A violência urbana, manifestamente pública e gratuita, tem mudado o padrão de sociabilidade dos citadinos. A cidade é um espaço cada vez mais privado da esperança de reduzir os riscos de vitimização, em função do medo da violência que segrega e distancia as classes na expectativa de escamotear esse comportamento. Entretanto, a violência possui muitas facetas e, de uma forma ou de outra, estará sempre presente enquanto produto do atrito social. É no contexto urbano e utilizando o tráfico de drogas como pano de fundo que este projeto de tese de doutorado buscará fazer considerações acerca da territorialização, bem como da disputa por espaços públicos em meio ao tráfico de drogas e se tal questão contribui diretamente na massificação da criminalização da pobreza e exclusão social. Com isso, este projeto irá utilizar como método de investigação o materialismo histórico dialético que se configura em um método para apreensão e conhecimento da realidade, a partir de uma abordagem abrangente dos fenômenos que supera o dualismo entre sujeito e objeto na construção do conhecimento. $\mathrm{O}$ objetivo é analisar a dinâmica do tráfico de drogas ilícitas, a partir das concepções de território, observando em que medida a apropriação do espaço contribui para a criminalização da pobreza, sobretudo nas disputas interpessoais. A cidade de Miracema foi tomada como objeto de observação em função de um conjunto de condicionantes, dos quais se destaca o histórico com o tráfico de drogas, sua importância no contexto regional e suas disparidades socioeconômicas.

Palavras chaves: violência urbana; tráfico de drogas; criminalização da pobreza.

\begin{abstract}
Urban violence, which is clearly public and free of charge, has changed the standard of sociability of city dwellers. The city is a space increasingly deprived of the hope of reducing the risks of victimization, due to the fear of violence that segregates and distances classes in the expectation of concealing this behavior. However, violence has many facets and, in one way or another, it will always be present as a product of social friction. It is in the urban context and using drug trafficking as a background that this doctoral thesis project will seek to make considerations about the territorialization as well as the dispute for public spaces in the midst of

\footnotetext{
${ }^{1}$ Mestre em Políticas Sociais. Doutorando em Sociologia Política (UENF). Professor do Curso de Serviço Social da Universidade do Estado de Minas Gerais

${ }^{2}$ Mestre em Serviço Social. Doutoranda em Serviço Social (UFRJ). Professora do Curso de Serviço Social da Universidade do Estado de Minas Gerais.

CSOnline - Revista Eletrônica de Ciências Sociais, Juiz de Fora, n. 25 (2017), pp. 1-296.
} 
drug trafficking and if such a question contributes directly to the massification of Criminalization of poverty and social exclusion. With this, this project will use as a method of investigation historical dialectical materialism that is configured in a method for apprehension and knowledge of reality, from a comprehensive approach to phenomena that overcomes the dualism between subject and object in the construction of knowledge. The objective is to analyze the dynamics of illicit drug trafficking, starting from the conceptions of territory, observing to what extent the appropriation of the space contributes to the criminalization of poverty, especially in interpersonal disputes. The city of Miracema was taken as an object of observation due to a set of constraints, which highlights the history of drug trafficking, its importance in the regional context and its socioeconomic disparities.

Keywords: urban violence; drug trafficking; Criminalization of poverty.

\section{INTRODUÇÃO}

Este artigo inscreve-se no rol de análises do contexto urbano e utilizando o tráfico de drogas como pano de fundo, buscando fazer considerações acerca da territorialização, bem como a disputa por espaços públicos em meio ao tráfico de drogas.

Segundo Cardia, Adorno e Poleto (2003, p.12), "a criminalidade violenta no Brasil, sobretudo, os homicídios no espaço urbano, tem crescido de modo acentuado desde a década de 1960, movimento sobreposto ao acelerado processo de urbanização vivenciado nas últimas décadas do século XX no país". E no município de Miracema não tem sido diferente: o espaço urbano tem se deparado cada vez mais com atos de criminalidades e homicídios.

Barcellos (2016), fala sobre isso em sua pesquisa de mestrado, a partir de uma fala do Promotor de Justiça de Miracema. Embora o mesmo não tenha apresentado uma precisão destas informações, faz-se necessário uma pesquisa como esta que se propõe para identificar essa relação do tráfico de drogas com os homicídios ocorridos neste município. Barcellos (2016) nos diz a respeito:

Em Miracema, de acordo com levantamento realizado no Ministério Público referente à entrada de processos dos últimos dois anos, foi verificado que grande parte dos atos infracionais cometidos pelos adolescentes estão ligados ao porte de droga para o consumo próprio, posse de arma de fogo, lesão corporal, ameaça, tráfico e homicídio.

CSOnline - Revista Eletrônica de Ciências Sociais, Juiz de Fora, n. 25 (2017), pp. 1-296. 
De acordo com o Promotor de Justiça do Município de Miracema, cerca de $80 \%$ dos homicídios ocorridos nesta cidade é relacionado diretamente com o uso e tráfico de drogas, com base nisto ele nos diz que: Em Miracema se compararmos com outros municípios da região, Miracema tem uma criminalidade mais assentada no tráfico de drogas, temos alguns casos notórios de práticas de atos infracionais por adolescentes praticados por usuários de drogas, temos alguns casos aqui muito emblemáticos de pessoas (adolescentes) que respondem a dez, doze processos por furto, por causa do uso de drogas. Tráfico de drogas em Miracema está muito presente na criminalidade... irei "chutar aqui por alto", mas de 80 a $90 \%$ de casos de tentativa de homicídio e homicídio estão vinculados a questão do tráfico de drogas e guerra de facções (BARCELLOS, 2016).

Com isso, podemos compreender que o modo de vida urbano, a mobilidade, as novas formas de sociabilidade em rede, a intensificação das trocas interpessoais efêmeras dos perfis virtuais, enfim, as mudanças no padrão cultural produziram novas formas de observação e de relacionamento com o meio e com o outro. Essa nova sociabilidade reforça o anonimato, o medo e a violência, mudando a postura das pessoas, principalmente, nas metrópoles e nas cidades de pequeno porte.

A escolha pela análise da violência urbana, categoria utilizada nesta pesquisa para instrumentalizar a discussão sobre o tráfico ilícito de entorpecentes, justifica-se por ser neste contexto que as disputas têm se intensificado, despertando o interesse de pesquisadores de diversas áreas do conhecimento.

A violência possui conceitos multidimensionais, sendo demonstrada desde o assédio moral no ambiente de trabalho, pelo tratamento desrespeitoso entre casais, pelos crimes patrimoniais como furtos e roubos, até a violência capital, exposta pelos homicídios.

A representação das formas de violência a partir do tráfico de drogas é muito dinâmica e complexa, portanto, de difícil mensuração e compreensão em grande escala. Por esse motivo, as cidades de pequeno porte, com menor influência da metrópole minimizam os efeitos de interferências externas, situação que projeta a cidade de Miracema como recorte espacial. 
Além disso, o crescimento repetido e desordenado, problemas ligados às desigualdades sociais e intensificação dos indicadores de violência, com destaque para os homicídios, completam os motivos pela escolha dessa cidade.

Para discussão da violência, principalmente em sua perspectiva urbana, a utilização da categoria território mostra-se relevante pela sua capacidade de representar a apropriação do espaço sob a influência do poder.

O território, enquanto conceito-chave, é utilizado em grande medida pelas diversas áreas do conhecimento, em função de sua capacidade representativa na leitura da apropriação do espaço. Neste projeto, as concepções sobre território auxiliarão na compreensão da existência de lutas entre traficantes por ponto de venda de drogas e por poder.

As disputas envolvendo traficantes materializam as questões conceituais contempladas nas abordagens territoriais. Os traficantes utilizam-se, por exemplo, de uma base material do território para estabelecerem seus pontos físicos de venda de drogas. Além disso, utilizam a base simbólica, ao sinalizar para outros grupos a existência de uma fronteira que representa um espaço de exclusividade, onde integrantes de outras facções não são bem-vindos.

O poder exercido por uma facção e a recorrência de determinados crimes em alguns espaços da cidade de Miracema revelaram a existência de uma disputa violenta pela demarcação de fronteiras territoriais.

Avalia-se que o estudo da temática, agora em nível de doutorado, irá propiciar respostas para as questões que vêm sendo construídas, permitindo conhecer e analisar criticamente aspectos importantes no que diz respeito ao território e o tráfico de drogas no município de Miracema.

\section{Violência Urbana: criminalização da pobreza e a disputa territorial do tráfico de drogas no município de Miracema - RJ.}

Para que essa proposta de estudo seja concretizada, é necessário destacar um conjunto de categorias que nos permitem delinear, inicialmente, o universo teórico onde CSOnline - Revista Eletrônica de Ciências Sociais, Juiz de Fora, n. 25 (2017), pp. 1-296. 
ela se desenvolverá. Nesta seção, localiza-se o discurso sobre o território, fazendo, assim, uma análise teórica do conceito. Logo, apresenta-se o município de Miracema, bem como suas particularidades históricas com a questão da drogadição e, por fim, discute-se sobre a criminalização da pobreza e sua relação com a disputa territorial.

\subsection{Identificando o território: localizando o discurso}

O conceito de território representa uma temática essencial para a análise espacial, uma vez que está diretamente relacionado aos processos de construção, controle, poder e dominação do espaço geográfico. É interessante a sua discussão na compreensão das transformações socioespaciais, não somente na ciência geográfica, na medida em que apresenta um caráter multidimensional e flexível que pode ser utilizado na análise de (re)produções econômicas, sociais e políticas, até mesmo em outras formas de relacionamentos do homem para com o espaço, principalmente, o espaço geográfico transformado pelas ações e pelas relações humanas.

A dimensão política atribuída à delimitação conceitual do território absorve outro significado no início do século XX. Esse período aparece vinculado ao poder exercido pelo indivíduo, que passa a dominar determinado espaço geográfico. Em outras palavras, o território deixa uma perspectiva meramente física ou política e ganha a perspectiva cultural ou imaterial, dando origem às mais diversas territorialidades marcadas pelo simbolismo de seus mais variados representantes.

Raffestin (1993) aborda o território por um viés distinto daquele tratado pela Geografia Política Clássica, o cerne para o estudo do território passa a ser as relações de poder. Nesse sentido, ganha especial atenção saber por quem o poder é exercido, bem como qual seria o seu fundamento ou intenção. $\mathrm{O}$ território por essa perspectiva passa a ser observado como espaço de apropriação, com uma delimitação parametrizada pelas relações de poder que são manifestadas em todos os níveis das relações sociais. Nas palavras do autor:

CSOnline - Revista Eletrônica de Ciências Sociais, Juiz de Fora, n. 25 (2017), pp. 1-296. 
O território se forma a partir do espaço, e é o resultado de uma ação conduzida por um ator sintagmático (ator que realiza um programa) em qualquer nível. Ao se apropriar do espaço, concreta ou abstratamente (por exemplo pela representação), o ator territorializa $o$ espaço. [...] o território nesta perspectiva é um espaço onde se projetou um trabalho, seja energia e informação, e que, por consequência, revela relações marcadas pelo poder. O espaço é a 'prisão original', o território é a prisão que os homens constroem para si (RAFFESTIN, 1993, p 143-144).

Em sua argumentação, Raffestin (1993) assegura que o poder e o espaço são duas concepções a serem consideradas na compreensão do território. Essa é uma referência importante, uma vez que a categoria espaço, para a Geografia, é como um substrato, uma liga da qual se originam os demais conceitos, concepções e análises. Nos estudos relacionados ao território, este é constantemente confundido com a questão do espaço. Todavia, vale ressaltar que as discussões sobre território são posteriores aos estudos sobre o espaço, uma vez que aquele ocorre após a apropriação do espaço e de acordo com as necessidades dos envolvidos. Para que ocorra o surgimento do território, é necessário que existam as relações de poder, que haja apropriação do espaço por pessoas ou instituições.

As análises de Raffestin (1993) indicam que o espaço é anterior ao território, e este é estabelecido e produzido ao se apoderar do espaço em qualquer escala, de forma concreta ou abstrata, o espaço é territorializado. Deste modo, o território é o lugar das relações, informações, energia, tendo como resultante o poder, dominação e apropriação.

Nessa mesma ideia, Dallabrida (1999, p. 2) alerta para a necessidade de distinção conceitual entre o território e o espaço, destacando que o conceito de “território não deve ser confundido com o de espaço ou de lugar, estando muito ligado à ideia de domínio ou de gestão de determinada área. Deve-se ligar o conceito de território à ideia de poder".

A definição do conceito de território é de fundamental importância para os estudos sobre o espaço geográfico e para compreensão dos mais diversos interesses que permeiam os espaços globais e locais. As relações que se instalam em determinado CSOnline - Revista Eletrônica de Ciências Sociais, Juiz de Fora, n. 25 (2017), pp. 1-296. 
espaço e a estrutura física construída pelo homem definem o território que ali se formará.

Raffestin (1993) faz uma abordagem do conceito de território marcado pelas relações de poder. O poder exercido pelo homem ou pelos grupos humanos que se transformam em categoria essencial para a compreensão desse conceito de território, uma vez que é inerente a todas as relações sociais.

A partir dessa ideia, surgiram novas linhas e novos estudos que consideram a perspectiva cultural e imaterial do território, tais como as utilizadas por Souza (2005, 2000), Santos (2002, 2006), Sack (1986; 1992; 1997; 2003), Haesbaert (2006), Sposito (2004) para subsidiar a discussão atual.

Haesbaert (2006), por exemplo, ao posicionar sobre o assunto, assegura que o território pode ser construído sob a perspectiva idealista, pela qual a cultura, códigos étnicos e a religião são formas de apropriação de um determinado espaço.

Saquet (2011) nos estudos sobre o território e a territorialidade fez o seu agrupamento em quatro perspectivas: a) econômica, b) materialista, c) fenomenológica, d) sustentabilidade ambiental e desenvolvimento local.

Nas observações de Haesbaert (1997), propõe-se uma tipologia sugerindo que o território pode ser classificado em quatro importantes concepções, que são: a política, a cultural, a econômica e a natural.

Para Santos (1994), a produção e fragmentação do território são realizadas de forma complexa, nas quais se configura um arranjo de relações complementares e contraditórias. Portanto, nota-se a importância do conceito de território, levando a compreender de forma gradativa a articulação das relações entre o lugar, a formação socioespacial e a constituição de uma rede de conexões nos mais variados lugares do mundo.

Sobre o assunto, Santos (2002b, p. 137) assevera que "É o uso do território, e não o território em si mesmo, que faz dele o objeto da análise social". Essa colocação evidencia a importância da apropriação, da manifestação do poder, da delimitação de fronteiras e da compreensão da função que indivíduos exercem nos mais variados espaços.

CSOnline - Revista Eletrônica de Ciências Sociais, Juiz de Fora, n. 25 (2017), pp. 1-296. 
Souza (2005) argumenta que o território não é o substrato, o espaço social em si, mas sim um campo de forças, em que são estabelecidas relações de poder delimitadas e que operam em um substrato referencial.

O autor exemplifica, em outra obra, que o território pode ser representado por grupo com amplitude e objetivos distintos, citando o poder exercido por uma gangue e por bloco de países que se associam para ampliação de suas defesas. Nas palavras do autor:

Território é fundamentalmente um espaço definido e delimitado por e a partir de relações de poder. Todo espaço definido e delimitado por e a partir de relações de poder é um território do quarteirão aterrorizado por uma gangue de jovens até o bloco constituído pelos países membros da OTAN. [...]. (SOUZA, 1996, p.78).

$\mathrm{O}$ autor completa afirmando que o conceito de território deve levar em conta as relações políticas que "constituem territórios, cartografados ou não, claramente delimitados ou não", desde que sejam manifestados em espaços urbanos como territórios do tráfico, da prostituição ou da segregação socioeconômica, sendo essas situações regionais, internacionais ou até mesmo globais. Nessa concepção destaca-se os apontamentos de Santos (2002, p. 9) sobre a questão, ao afirmar que:

O Território é o lugar em que desembocam todas as ações, todas as paixões, todos os poderes, todas as forças, todas as fraquezas, isto é onde a história do homem plenamente se realiza a partir das manifestações da sua existência. A Geografia passa a ser aquela disciplina mais capaz de mostrar os dramas do mundo, da nação, do lugar.

Como alternativa para superar a distinção entre espaço social e território, Souza (2000) propõe "descoisificá-lo" a partir do refinamento conceitual, enriquecendo seu arsenal de possibilidades de definição. $O$ autor argumenta que o espaço social é multifacetado e o território (a territorialidade) é uma dessas facetas.

Para Lefebvre (2000), o espaço (social) é um produto (social): ele é um meio de produção e de controle que escapa parcialmente aos que dele se servem. Assim, as CSOnline - Revista Eletrônica de Ciências Sociais, Juiz de Fora, n. 25 (2017), pp. 1-296. 
forças sociais e políticas (estatistas) que o engendram tentam em vão controlá-lo. Esse espaço é abstrato, mas também real, concreto, instrumental. A especificidade desse espaço social surge quando ele não mais se confunde com o espaço mental (dos filósofos e matemáticos) e com o espaço físico (definido pelo prático-sensível e pela percepção da "natureza"). Ele tampouco se reduz a uma coleção de coisas ou a um vazio preenchido, a uma forma imposta à materialidade, na medida em que ele contém relações sociais. O que interessa é o espaço como totalidade ou globalidade, não reduzido às coisas localizadas no ou sobre o espaço.

É exatamente a territorialidade do tráfico, manifestamente no viés da violência, que interessa observar a fragmentação e o domínio do espaço. O poder exercido por traficantes em determinadas áreas movimenta as fronteiras do território, produzindo dinâmicas diferenciadas no espaço social.

Para compreender de que maneira o tráfico de drogas fragmenta os espaços produzindo territórios em que os crimes são mais frequentes ou aqueles em que o comércio de drogas é mais intenso e/ou violento, Souza (2005, p. 79) orienta que é necessário saber "quem domina ou influencia e como domina ou influencia esse espaço? [e também] quem influencia ou domina quem nesse espaço, e como?”.

Nesse sentido, verifica-se que os resultados em relação à movimentação do território, seja apropriação, dominação ou influência dependerá dos objetivos de quem (re)produz a fragmentação. Isso sinaliza para análise de distintas formas de territorialização do espaço na perspectiva da violência, permitindo construções metodológicas que ora podem ser representadas por roubo, ora por tráfico, ora por homicídio.

Aliados ao território, processos e as formas espaciais urbanas auxiliam na compreensão da dinâmica da criminalidade e da violência. A cidade de Miracema permite observar que esses processos e formas espaciais comuns a algumas cidades brasileiras auxiliam no empoderamento de argumentos explicativos ao comportamento criminal. 


\subsection{Miracema - RJ: uma caracterização socioespacial e suas particularidades com as drogas}

Para compreender melhor algumas variáveis envolvidas na territorialização da criminalidade e da violência urbana, Miracema foi tomada como recorte de estudo, como forma de facilitar o exercício analítico de variáveis que podem contribuir com a compreensão da manifestação da criminalidade e violência no espaço e no tempo.

O município de Miracema é pertencente à Região Noroeste Fluminense, com proximidades aos municípios do Estado de Minas Gerais, situando-o na rota do tráfico de drogas da região, ocupa o terceiro lugar na Região Noroeste no que se refere aos indicadores de pobreza e desigualdade, como demonstra o Índice do Mapa de Pobreza e Desigualdades dos Municípios Brasileiros - 2003, do Instituto Brasileiro de Geografia e Estatística (IBGE).

De acordo com o censo de 2010, Miracema tem uma população de 26.786 habitantes e o Índice de Desenvolvimento Humano Municipal (IDHM) é de 0,713, em 2010, classificando-o como índice médio de desenvolvimento humano em sua ocupação na $72^{\circ}$ posição no critério do IDH estadual.

O município de Miracema-RJ apresenta peculiaridades interessantes que devem ser destacada no manejo sobre drogas. Desde a década de 90, o município esteve em evidência no que tange ao tráfico de drogas em noticiários sobre criminalidade envolvendo a problemática. $\mathrm{O}$ mesmo localiza-se em um ponto estratégico para este comércio, visto que faz divisa com Minas Gerais (está a aproximadamente $18 \mathrm{~km}$ de um município do Estado de Minas, Palma-MG) e localiza-se próximo ao município de Itaperuna, que por ter se tornado uma cidade universitária, abarca uma grande população migrante, comdeslocamento de indivíduos dentro de um espaço geográfico, de forma temporária.

As denominações dadas ao município refletem a sua representação pela população, como as de "miraconha" e "miraína", apelidos estes que fazem alusão ao envolvimento municipal à maconha e cocaína. Atualmente, pela grande proliferação do

CSOnline - Revista Eletrônica de Ciências Sociais, Juiz de Fora, n. 25 (2017), pp. 1-296. 
crack na periferia, o município tem sido apelidado de "miracrack" (BARCELLOS, 2016).

Barcellos (2016) buscou identificar em seu estudo, a partir de um levantamento de dados realizados no CAPS - Centro de Atenção Psicossocial de Miracema, o território em que estes usuários de drogas do município estão localizados, pois, de acordo com Souza (2005, p. 84), a ocupação do território é vista como algo gerador de raízes e identidade. Assim, um grupo não pode ser mais compreendido sem o seu território, no sentido de que a identidade sócio-cultural das pessoas estaria inarredavelmente ligada aos atributos do espaço concreto (natureza, patrimônio arquitetônico, "paisagem") e mais. Os limites do território não seriam, é bem verdade, imutáveis - pois as fronteiras podem ser alteradas, comumente pela força bruta - mas cada espaço seria, enquanto território, território durante todo o tempo, pois apenas a durabilidade poderia, é claro, ser geradora de identidade socioespacial, identidade na verdade não apenas como espaço físico, concreto, mas com o território e, por tabela, com o poder controlador desse território.

Pautado neste contexto, e a partir dos dados encontrados, identificou-se que a maioria destes usuários se encontra residindo nas comunidades do morro do Cruzeiro, Cehab, Viradouro, Vila Nova e Jove. Ressalta-se que estas comunidades possuem uma característica em comum de extrema relevância que é a falta de acesso às políticas públicas e sociais, não apenas por falta das mesmas, mas também, e principalmente, por falta de conhecimento de como ter acesso a tais serviços. Diante disso, existe a clara necessidade de um trabalho significativo de conscientização de direitos sociais, pois muitas das vezes os mesmos deixam de usufruir por desconhecimentos dos dispositivos e equipamentos existentes na região. Consequentemente, resvalam na ociosidade, recorrendo a atos ilícitos que muitas das vezes levam ao tráfico, até mesmo para subsidiar o próprio consumo de sua droga de preferência.

Uma característica de extrema importância a respeitos desses bairros é que os mesmos encontram-se divididos por instâncias de poder paralelo, denominado facções criminosas, que regulam as ações e determinam o cotidiano de tais comunidades. No momento, os bairrosestão divididos da seguinte maneira: Cehab, Vila Nova e Jove são CSOnline - Revista Eletrônica de Ciências Sociais, Juiz de Fora, n. 25 (2017), pp. 1-296. 
comandadas pelo TCP (Terceiro Comando Puro) e os bairros Cruzeiro, Viradouro e Carrapichão pelo CV (Comando Vermelho). Os confrontos entre as facções acontecem periodicamente; a motivação consiste sempre na disputa de territórios, podendo haver mudanças a qualquer momento. Conforme demonstra mapa a seguir, a cidade está divida pelas facções:

\section{FIGURA 01: Miracema dominada pelo tráfico}

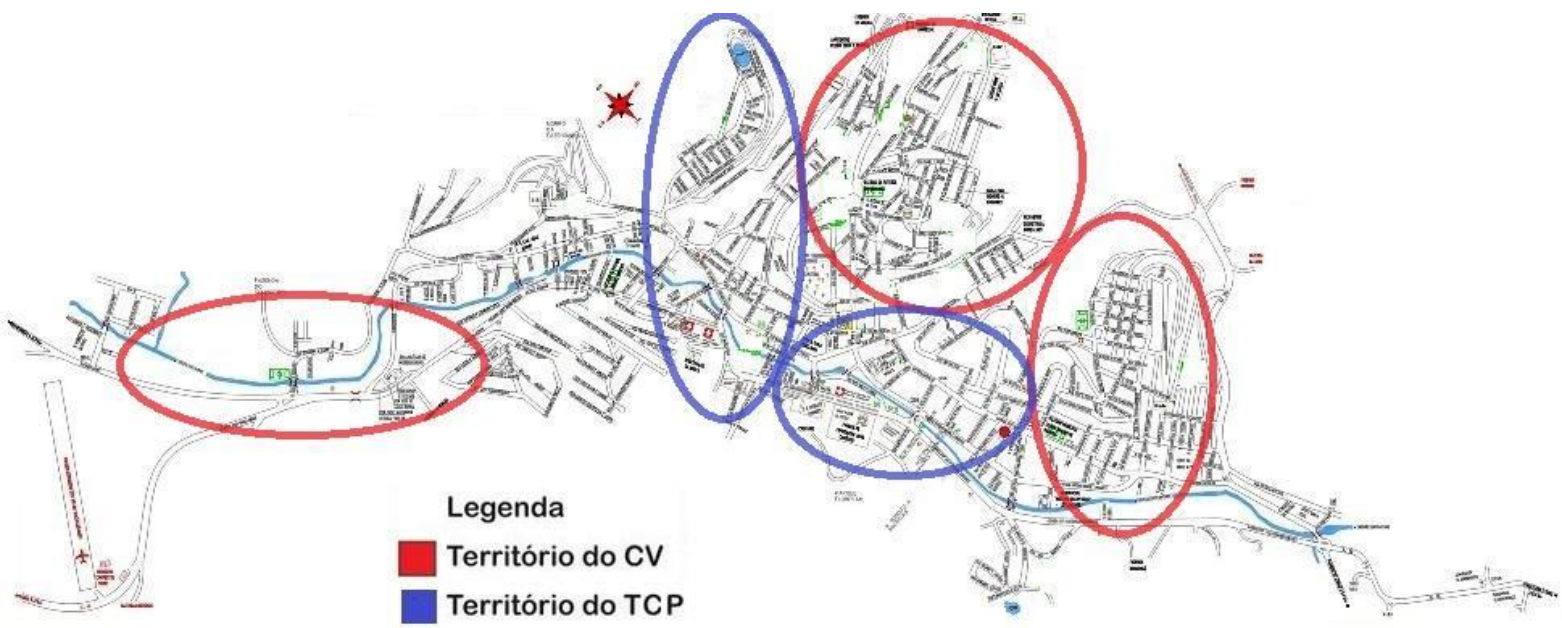

Fonte: Elaboração própria

Facções estas que tem sua origem no Rio de Janeiro, sendo a mais antiga o Comando Vermelho (CV). A facção surgiu na década de 70 no presídio da Ilha Grande, em Angra dos Reis, no Sul Fluminense, com o nome de Falange Vermelha, a partir do contato entre presos políticos e criminosos comuns.

Nos anos 80, o CV passou a ocupar morros na cidade, como o Juramento, em Vicente de Carvalho, na zona norte, reduto de José Carlos dos Reis Encina, o Escadinha, e atuar no tráfico de drogas. A base de atuação do grupo era o Complexo do Alemão.

CSOnline - Revista Eletrônica de Ciências Sociais, Juiz de Fora, n. 25 (2017), pp. 1-296. 
Com a ocupação da área pela Força de Pacificação do Exército, as principais favelas do CV passaram a ser o Jacarezinho e Manguinhos, na mesma região. Seus maiores líderes são Luiz Fernando da Costa, o Fernandinho Beira-Mar e Márcio dos Santos Nepomuceno, o Marcinho VP, ambos presos.

O Terceiro Comando Puro (TCP) foi criado em 2002 após um racha entre o antigo Terceiro Comando (TC) e a ADA (Amigos dos Amigos) que, embora fossem facções diferentes, eram unidos. Suas principais áreas são os complexos de Senador Camará, na zona oeste, e o da Maré, na zona norte.

Fica claro que houve uma interiorização destas facções, chegando assim a cidades de pequeno porte como é o caso da cidade utilizada como recorte nesta pesquisa. E hoje as mesmas dominam boa parte do território do município, incitando assim a violência e a propagação da criminalidade.

Abaixo seguem algumas imagens de pichações de casas, postes e prédios públicos nestas comunidades, demonstrando o reconhecimento daquela comunidade como pertencente a determinada facção do tráfico de drogas:

FIGURA 02: A jove e as marcações do TCP

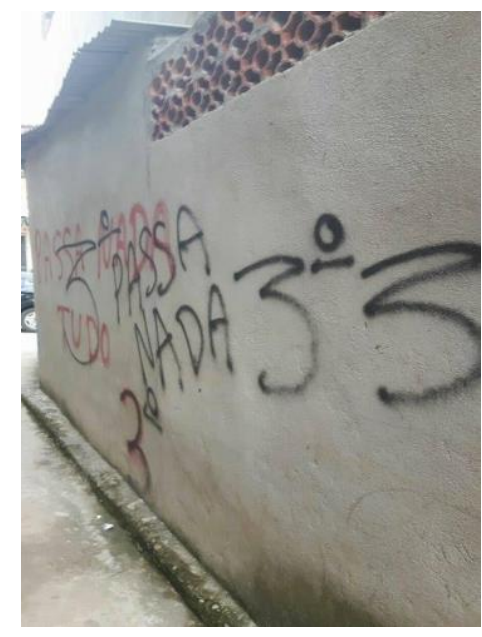

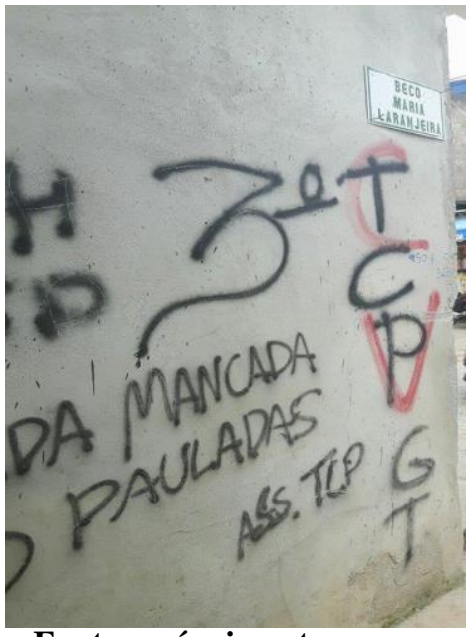

Fonte: próprio autor

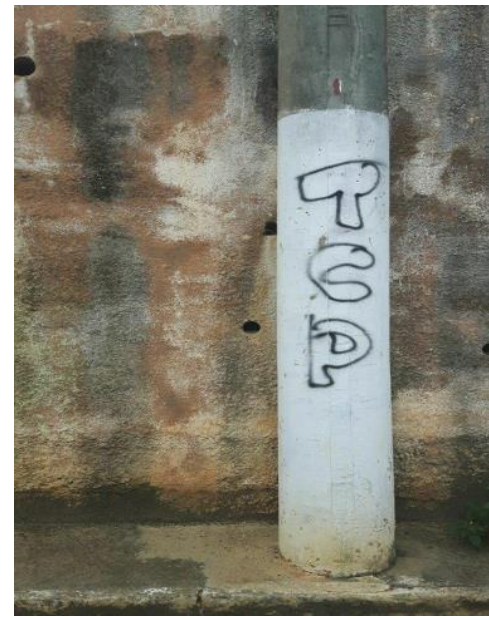

As fotos acima foram tiradas no Morro da Jove, localidade com forte envolvimento onde ocorrem diversos confrontos entre facções por disputa de territórios, como demonstram as pichações acima o espaço era comandando pelo CV e o TCP passou a dominar este território. As próprias pichações são marcadas por ameaças CSOnline - Revista Eletrônica de Ciências Sociais, Juiz de Fora, n. 25 (2017), pp. 1-296. 
dizendo que: "em caso de mancadas terão pauladas". Isso demonstra como tais espaços são marcados pelo medo e ameaças àquela comunidade.

A seguir estão as fotos de pichações na comunidade do Carrapichão, local que recentemente veio acolher um conjunto habitacional que foi inaugurado no ano de 2012 e, desde então, graves problemas sociais foram surgindo e principalmente no que tange à drogadição e o tráfico de drogas. Esta comunidade vive em constantes oscilações de dominação e neste momento como demonstram as pichações vem sendo "gerenciada" pelo $\mathrm{CV}$.

\section{FIGURA 03: O carrapichão demarcado pelo tráfico}
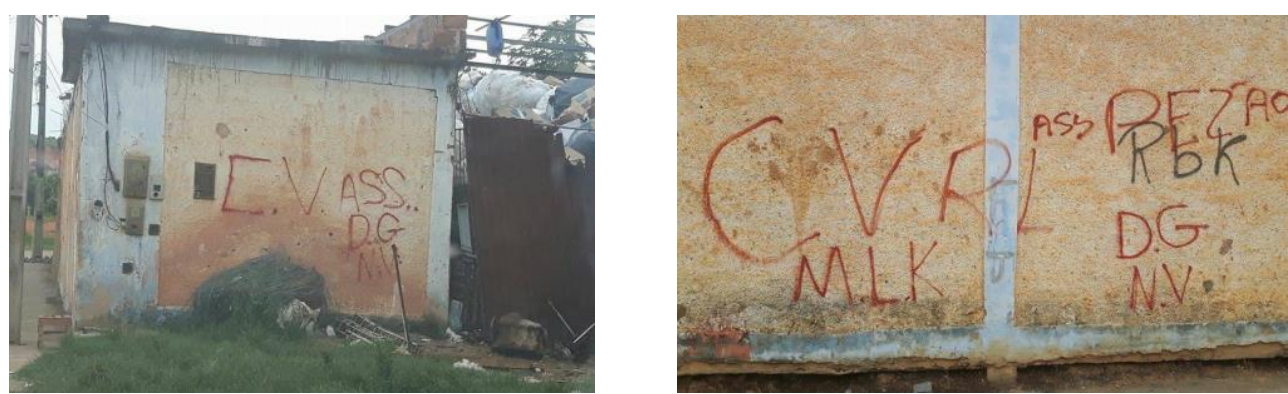

Fonte: próprio autor

A comunidade carrapichão ainda não disponibiliza nenhum recurso de atendimento, como serviços de atenção à saúde básica, equipamentos de assistência social, dentre outros, tornando necessária a utilização de todos os recursos públicos em outro bairro, denominado Pontilhão do Rosa. Mediante a tal contexto, ressalta-se a necessidade que esta comunidade seja acompanhada pelos dispositivos da Rede de Atenção Psicossocial para assim buscar formas de contribuir para melhoria da qualidade de vida das pessoas que residem nesta localidade.

Seguem abaixo ainda algumas fotos retiradas no alto do Cruzeiro, localidade também gerenciada pelo Comando Vermelho, como demonstram as pichações:

\section{FIGURA 04: $O$ cruzeiro é dominado pelo CV}

CSOnline - Revista Eletrônica de Ciências Sociais, Juiz de Fora, n. 25 (2017), pp. 1-296. 

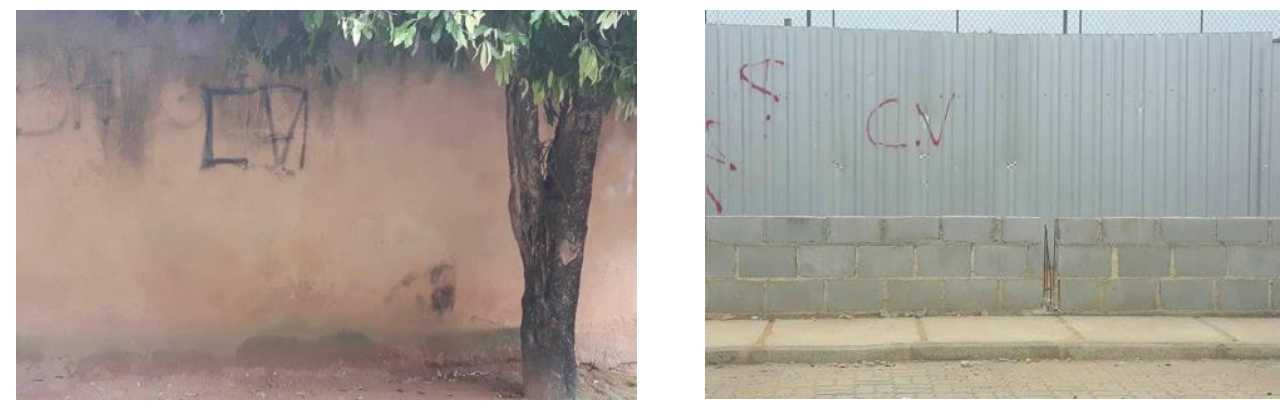

Fonte: próprio autor

As imagens apresentadas demonstram como a cidade de Miracema encontra-se demarcada territorialmente pela disputa de poder de facções criminosas e o descaso do poder público em não intervir nestas situações que afligem tanto a população. Mediante a tal problemática torna-se clara e urgente a necessidade de maior intervenção estatal nesses espaços a fim de que sejam minimizados tais danos, que são causados na vida de toda a população miracemense, que acaba sendo vitimada de maneira geral, mediante ao atual quadro de insegurança e violência, ao qual são expostos dentro desta configuração de dinâmica cotidiana.

\subsection{A disputa territorial e a criminalização da pobreza}

A pobreza, por muito tempo, tem sido criminalizada pelas forças dominantes em seus mais variados contextos. Fazendo uma breve (ou aprofundada) reflexão sobre a História do Brasil, facilmente se perceberá que os pobres nunca tiveram lugar de prestígio na sociedade, ora nobre, ora burguesa. Assim sendo, as pessoas têm se acostumado, no decorrer dessas várias décadas, a vislumbrar-la sempre como um mal obstinado a dificultar a ascensão do país ao patamar das nações desenvolvidas.

Muito se tem falado de criminalização da pobreza nos dias atuais. A relação entre ações violentas e camadas pobres tem sido veiculada cotidianamente pelos meios de comunicação e sem sombra de dúvida é o tema atual do debate público, e em torno deste se vem produzindo uma acalorada discussão nas ciências humanas.

Criminalizar, como a própria palavra indica, significa configurar uma ação, seja ela individual ou coletiva, como um crime. Esse processo de criminalização da pobreza, CSOnline - Revista Eletrônica de Ciências Sociais, Juiz de Fora, n. 25 (2017), pp. 1-296. 
quando generalizadamente constrói a visão da comunidade pobre como um grupamento de criminosos traz consigo uma enorme carga de estigma que tem consequências para a realização dos direitos mais básicos dessa população.

Sobre o fator criminalidade, Zaluar (1994) argumenta que esta não é um efeito direto da pobreza dos habitantes destas áreas mais desfavorecidas da cidade. Para entendê-la, torna-se necessário levar em conta um conjunto de outros fatores, como o fim das relações personalizadas entre pobres e ricos; o afastamento dos filhos em relação aos pais; as dificuldades dos jovens em obter uma formação adequada e, portanto, um emprego; as práticas discriminatórias da polícia em relação aos jovens das áreas pobres; e ainda a emergência de uma subcultura, que desqualifica o trabalho como meio de obtenção de recursos e atribui prestígio às manifestações de força mediante emprego de armas de fogo e à posse de bens tidos como privativos dos ricos, sobretudo as vestimentas inacessíveis aos pobres.

Atualmente fica claro que existem rótulos a grupos vulneráveis como uma classe perigosa e no município de Miracema isso está muito evidente, mediante a disputa territorial que tem sido travada entre facções criminosas CV e TCP, fortalecendo a criminalização da pobreza, visto serem oriundos de comunidades extremamente carentes, com diversas pessoas que não são partícipes do tráfico de drogas e acabam recebendo este rótulo pelo simples fato de ser pobre, negro e morar em uma comunidade dominada pelo tráfico de drogas, tendo suas oportunidades de crescimento profissional reduzida em meio a tanto preconceito.

O processo de estigmatização e de criminalização por qual tem passado essas famílias pobres, e que muitas das vezes tem o respaldo dos meios de comunicação, passa pelo não reconhecimento desta sociabilidade enquanto legítima, além de ser um processo intrinsecamente político. A criminalização da pobreza é também ligada em sua essência ao recrudescimento da exclusão social, causada pela implementação do neoliberalismo. A desigualdade social aliada à instauração de uma sociedade de consumo e à ausência de políticas públicas efetivas e de acesso aos direitos sociais são fatores que certamente repercutem atualmente no aumento da criminalização da pobreza em meio a estes territórios dominados pela criminalidade.

CSOnline - Revista Eletrônica de Ciências Sociais, Juiz de Fora, n. 25 (2017), pp. 1-296. 
Portanto, é preciso atentar para diferentes consequências da representação difundida sobre esses espaços marcados simbolicamente, como a favela, o gueto e também sobre o espectro variado que engloba o mundo social. Além disso, como ignorar as especificidades históricas e locais na aplicação desses conceitos a diferentes sociedades? A diferença dos instrumentos teóricos surgidos, nas últimas décadas, para abordar os contrastes e desigualdades sociais suscita questões de alcance político, conforme observam Bourdieu e Wacquant. Essas diferenças no campo teórico têm estreitas relações com o modo com que os espaços urbanos relegados às populações pobres são representados nas diversas áreas de produção cultural e artística. No caso do Brasil, cabe pensar, por exemplo, na concepção de "exclusão social” e suas implicações, em especial quando substitui o emprego da perspectiva de desigualdade. Quanto a um uso generalizado do termo "exclusão" social, lembram esses sociólogos que comumente está relacionado à despolitização e ao silêncio quanto às circunstâncias que cercam o desemprego e outras repercussões das políticas econômicas implantadas no fim do século XX e que preconizavam a instauração de um "Estado mínimo", descomprometido do atendimento de necessidades básicas da população (BOURDIEU; WACQUANT, 2005, p. 225).

\section{CONSIDERAÇÕES FINAIS}

A investigação de assuntos relacionados à violência, em especial àqueles vinculados à construção de territórios do tráfico, perpassa pelo reconhecimento de que o pesquisador deverá se debruçar em um ambiente inóspito no qual não se sabe, necessariamente, o caminho identificado inicialmente para melhor condução dos trabalhos a serem executados conforme planejado. A orientação metodológica inicial é muito mais uma sugestão para a realização do trabalho, uma vez que a interação com os sujeitos ou grupos, na realização de uma pesquisa social, nem sempre transcorre como idealizado, sendo necessários ajustes na execução.

Este estudo incide sobre uma análise da perspectiva de território, tendo como pano de fundo a comercialização de drogas ilícitas no espaço urbano da cidade de CSOnline - Revista Eletrônica de Ciências Sociais, Juiz de Fora, n. 25 (2017), pp. 1-296. 
Miracema - RJ, por entender que a intencionalidade dos sujeitos envolvidos nessa prática permite identificar de que maneira o espaço é apropriado e fragmentado sob a forma de territórios, bem como o modo pelo qual se estabelecem as práticas que levam à resolução violenta dos conflitos.

Por se tratar de um fenômeno dinâmico e, portanto, de difícil mensuração em grande escala, opta-se, em primeiro lugar, pela escolha de uma cidade de porte pequeno e com menor influência das regiões metropolitanas, uma vez que se minimiza o impacto que a confluência urbana em grande escala poderia produzir na análise dos dados.

A cidade de Miracema está localizada no Noroeste Fluminense do Estado do Rio de Janeiro. Nessa medida, em segundo lugar, faz-se um recorte espacial para facilitar o entendimento da dinâmica da criminalidade e das relações de poder que permeiam essas práticas na zona urbana. A escolha ocorre pela dinâmica causada pelos problemas das desigualdades, principalmente sociais, com destaque para o aumento da violência. Apesar da criminalidade não ser um fenômeno exclusivo de Miracema, apresentando recrudescimento no Brasil e no Rio de Janeiro de modo mais genérico, é na cidade interiorana que seu estudo é mais carente, uma vez que nem todo pesquisador se interessa pelo padrão criminal apresentado por cidades de pequeno e médio porte.

Nesse sentido, este trabalho teve como objetivo geral analisar a dinâmica do tráfico de drogas ilícitas a partir das concepções de território, observando em que medida a apropriação do espaço contribui para uso da violência nos conflitos sociais. Especificamente: a) estabelecer relações entre a espacialização dos delitos criminais e territórios do tráfico de drogas na cidade de Miracema, b) identificar a área de atuação dos distintos grupos que exercem o tráfico de drogas ilícitas, territorializando sua área de influência; c) construir uma possível hierarquização do território a partir das áreas de atuação das facções criminosas em Miracema e d) estabelecer relação entre a espacialização dos delitos criminais, os territórios do tráfico de drogas e as transformações socioespaciais na cidade de Miracema.

\section{REFERÊNCIAS}

CSOnline - Revista Eletrônica de Ciências Sociais, Juiz de Fora, n. 25 (2017), pp. 1-296. 
ARAÚJO, Liana Brito de C. A Questão do Método em Marx e Lukács: o desafio da reprodução ideal de um processo real. 2007. Disponível em: <www.ppgte.cefetpr.br/gtteanped/trabalhos/lianabritoaraujot09.rtf>. Acesso em: 23 de set. 2016.

BARCELLOS, W. S. O PROBLEMA DO CRACK: políticas sociais, intervenções e o cenário de Miracema - RJ. 2016. 127 fls. Campos dos Goytacazes, RJ. Originalmente apresentada como dissertação de mestrado em Políticas Sociais no Programa de Pós-Graduação em Políticas Sociais da Universidade Estadual do Norte Fluminense, RJ, 2016.

BOURDIEU, P.; WACQUANT, L. A astúcia da razão imperialista. In: WACQUANT, L. (org.). O mistério do ministério: Pierre Bourdieu e a política democrática. Rio de Janeiro: Revan, 2005. 232p

CÁRDIA, Nancy; ADORNO, Sérgio \& POLETO, Frederico (2003) Homicídio e violação de direitos humanos em São Paulo. Estudos Avançados, São Paulo, v. 17, nº 47, p. 43-73.

DALLABRIDA, Valdir Roque. Novos paradigmas para o desenvolvimento regional. 1999. Disponível em: <http://www.dge.uem.br//geonotas/vol3-1/ dala.html>. Acesso em 25 de abril de 2016.

HAESBAERT, Rogério. Territórios Alternativos. São Paulo: Contexto, 2006.

IAMAMOTO, M. V. Serviço Social em tempo de capital fetiche: capital financeiro, trabalho e questão social. 3. ed. São Paulo: Cortez, 2008.

LEFEBVRE, H. A produção do espaço. Trad. Doralice Barros Pereira e Sérgio Martins (do original: La production de l'espace. $4^{\circ}$ Ed. Paris: ÉditionsAnthropos, 2000). Primeira versão: início - fev. 2006.

KOSÍK, K. A dialética do concreto. Rio de janeiro: Paz e Terra, 1989.

MINAYO, Maria Cecília de Souza.; DESLANDES, Suely Ferreira; NETO, O. C.; GOMES, Romeu. Pesquisa social: teoria, método e criatividade. Petrópolis, RJ: Vozes, 1994. Miller (1970)

ORLANDI, E. P. Análise de Discurso: princípios e procedimentos. Campinas, SP: Pontes, 2001.

RAFFESTIN, Claude. Por uma Geografia do Poder. São Paulo: Ática, 1993. 269 p.

SACK, Robert. The humanterritoriality - its theoryandhistory. Cambridge, Cambridge University Press, 1986. 400 p. 
SANTOS, Milton. O lugar Encontrando o Futuro. Conferência de abertura do Encontro Internacional: Lugar, Formação Sócio Espacial, Mundo. São Paulo. Anpege. Departamento de Geografia da USP. 1994.

A Natureza do Espaço: Técnica e Tempo, Razão e Emoção.

4. ed. 2. reimpressão. - São Paulo: Editora da Universidade de São Paulo, 2006.

SANTOS, Milton et al. Território e sociedade: entrevista com Milton Santos. São Paulo: Editora Fundação Perseu Abramo, 2000.

SANTOS, Milton; Souza, Maria Adélia A; SILVEIRA, Maria L. Território, Globalização e Fragmentação. 5a ed. SP: HucitecAnpuz, 2002.

SAQUET, Marcos Aurélio. Por uma Geografia das territorialidades e das temporalidades: uma concepção multidimensional voltada para a cooperação e para o desenvolvimento territorial. São Paulo: Outras Expressões, 2011.

SPOSITO, Eliseu Savério. Sobre o conceito de território: um exercício metodológico para a leitura da formação territorial do sudoeste do Paraná. In: RIBAS, A. D.; SPOSITO, E. S.; SAQUET, M. A. Território e Desenvolvimento: diferentes abordagens. Francisco Beltrão: Unioeste, 2004.

SOUZA, Marcelo Lopes. O desafio metropolitano - Um estudo sobre a problemática sócio-espacial nas metrópoles brasileiras. Rio de Janeiro, Editora Betrand Brasil, 2000. 366 p.

As drogas e a "questão urbana" no brasil. A dinâmica sócio-espacial nas cidades brasileiras sob a influência do tráfico de tóxicos. IN: Iná Elias de Castro, Paulo Cesar da Costa Comes e Roberto Lobato Corrêa (organizadores). Brasil: Questões Atuais Da Reorganização Do Território, $5^{\text {a }}$ edição, BERTRAND BRASIL, 1996. p.419-164.

Clima de Guerra Civil? Violência e Medo nas Grandes Cidades Brasileiras. In: Edu Silvestre de Albuquerque (Org). Que País é Este? Pensando o Brasil Contemporâneo. São Paulo: Ed. Globo, 2005.

TEIXEIRA, A. (Org.) Utópicos, heréticos e malditos: os precursores do pensamento social de nossa época. Rio de Janeiro: Record, 2002.

ZALUAR, A. Condomínio do diabo. Rio de Janeiro, Revan e UFRJ, 1994. 